\title{
Utilização da própolis verde no efeito cicatrizante em lesão cutânea: relato de caso
}

\author{
Use of green propolis in the healing effect in cutaneous injury: case report
}

\author{
Mônica Barbosa de Sousa Freitas \\ Mestre em Gestão da Saúde pela Flórida Chrsitian University - FCU. E-mail: mbarbosadesousafreitas@ gmail.com.
}

José Cândido da Silva Nóbrega

Graduado em Administração e Mestre em Sistemas Agroindustriais-UFCG. E-mail:jcandidosn@uol.com.br

\section{Wyara Ferreira Melo}

Graduada em Enfermagem e doutoranda em Engenharia de Processos pela Universidade Federal de Campina Grande UFCG. E-mail: wyarafmelo@gmail.com.

\author{
Karla da Nóbrega Gomes \\ Graduada em Enfermagem e Mestre em Sistemas Agroindustriais pela Universidade Federal de Campina Grande - \\ UFCG. E-mail: karlindagomes@ hotmail.com.
}

\author{
Manoel Marques de Souto Nóbrega Filho \\ Graduando em Medicina pela Faculdade de Ciências Médicas da Paraíba - FCM-PB E-mail: \\ manoelmarquesnobrega@gmail.com.
}

\begin{abstract}
Resumo: O estudo tem como objetivo relatar a evolução do tratamento de feridas utilizando o extrato da própolis verde. Uma paciente do sexo feminino, 52 anos, procurou assistência médica para uma avaliação no Membro Inferior Esquerdo (MMII), uma lesão cutânea, sofrida após duas semanas do ocorrido. Orientou-se medicamentos para o processo de reparação da ferida como, um antibiótico Levofloxacino de 500mg com posologia de 12/12 e um analgésico Dievari de $900 \mathrm{mg}+100 \mathrm{mg}$. Após uma segunda avaliação externa, observou-se que as feridas apresentavam formato assimétrico, profundas, edemaciado, com um formato numular, apresentando mialgia no membro ao deambular e ao deitar-se. A dor relatada pela paciente antes de iniciar o tratamento de 0 a 10 de acordo com a Escala Visual Analógica - EVA, foi 9, significando dor intensa. A própolis foi utilizada na lesão. $\mathrm{Na}$ assepsia foram utilizados luvas, gazes, soro fisiológico, sabonete antisséptico Riohex de $2 \%$ de Digliconato de Clorexidina, água oxigenada de 10 volumes de $100 \mathrm{ml}$ e o extrato de própolis verde. O procedimento foi realizado durante oito dias, até obter o resultado de reparação da lesão. No relato de caso, a própolis verde durante a aplicação do protocolo, contribuiu para o processo de reparação do tecido, ocasionando a diminuição do processo inflamatório e a redução do nível de dor para 0 , de acordo com a Escala Visual Analógica EVA. É importante verificar a ação da própolis verde na ação curativa de feridas, sendo necessário estudos mais aprofundados, analisar as concentrações do extrato de própolis e outros fatores que possam garantir a ação desse produto.
\end{abstract}

Palavras-chaves: Tratamentos alternativos. Apis mellifera. Ferimentos.

\begin{abstract}
The study aims to report the evolution of wound treatment using green propolis extract. A 52-year-old female patient sought medical assistance for an evaluation on the Left Lower Limb (lower limb), a skin lesion suffered after two weeks of the event. Medicines were directed to the wound repair process, such as a 500mg Levofloxacin antibiotic with $12 / 12$ dosage and a $900 \mathrm{mg}+100 \mathrm{mg}$ Dievari analgesic. After a second external evaluation, it was observed that the wounds were asymmetrical, deep, swollen, with a numeral shape, presenting myalgia in the limb when walking and lying down. The pain reported by the patient before starting treatment from 0 to 10 according to the Visual Analogue Scale - EVA, was 9, meaning severe pain. Propolis was used in the lesion. Gloves, gauze, saline, 2\% Riohex antiseptic soap of Chlorhexidine Digliconate, hydrogen peroxide of 10 volumes of $100 \mathrm{ml}$ and green propolis extract were used for asepsis. The procedure was carried out for eight days, until the result of repairing the lesion was obtained. In the case report, green propolis during the application of the protocol, contributed to the tissue repair process, causing a decrease in the inflammatory process and a reduction in the pain level to 0, according to the Visual Analogue Scale - EVA. It is important to verify the action of green propolis in the healing action of wounds, requiring further studies, analyzing the concentrations of propolis extract and other factors that can guarantee the action of this product.
\end{abstract}

Keywords: Alternative treatments. Apis mellifera. Wounds. 


\section{INTRODUÇÃO}

A pele é considerada o maior órgão do corpo humano, com $16 \%$ total do peso corpóreo do individuo, contendo uma área de $20.000 \mathrm{~cm}^{2}$, com um volume 4000 $\mathrm{ml}$, contendo $30 \%$ de vasos cutâneos de sangue circulante. o tecido ocasiona revestimento e protege o organismo contra agentes nocivos físicos, químicos ou biológicos, atuando com ação imunológica, termorregulação, perceptiva e secretória. A pele é um órgão que mais sofre alterações, pois está sempre exposto ao meio ambiente, além de mutações fisiológicas desencadeadas pelo envelhecimento e aos hábitos diários (REIS, 2011). De acordo com (BRASIL, 2008; REIS, 2013) relatam que as lesões cutâneas no Brasil acometem a população de forma em geral no país, independentemente de sexo, idade ou etnia.

Pinheiro et al (2014) ressalta sobre a integridade cutânea relatando sobre a proteção que se considera um indicativo de qualidade de cuidados, e essas lesões acometem indivíduos em várias fases da vida, necessitando de cuidados baseados em áreas voltadas para neonatologia, pediatria, adulta e geriatria. Sendo lesões classificadas como aguda ou crônica, primárias ou secundárias a outros tipos de afecções, advindos de contextos clínicos ou cirúrgicos e associados ou não com doenças crônicas não transmissíveis, como hipertensão arterial sistêmica e diabetes mellitus.

Em séculos passados historiadores ressaltavam a maneira de como eram tratadas as feridas cutâneas que segundo Blanes (2004) na antiguidade as feridas eram tratadas para alcançar resultados cicatriciais em menor tempo possível. Na época da pré-história utilizavam agentes como: extratos de plantas, água, gelo, frutas, e lama que eram meios submetidos sobre a ferida. $\mathrm{Na}$ era mesopotâmica as feridas eram lavadas com água ou leite e o curativo era através de mel e resina. Nas coberturas usavam lã de carneiro, folhas e cascas de árvores. Segundo os egípcios as feridas fechadas eram consideradas mais rápidas na cicatrização que as abertas, por isso, eram utilizadas tiras de pano nas margens da ferida. Hipócrates na época sugeria que as feridas contusas fossem tratadas com calor e pomada com o objetivo de promover a supuração, remover a área necrosada, e diminuir a inflamação. $\mathrm{Na}$ era cristã se preconizava primeiramente o fechamento das feridas recentes e o desbridamento das contaminadas para logo após serem suturadas. No passar dos anos tratamentos de feridas foram se evoluindo, através da química descobriram os compostos de iodo e o cloro que eram utilizados pra limpeza do material e assepsia da pele nos séculos XVIII e XIX. As feridas causam ao ser humano portadores e familiares alguns sintomas como: dor permanente, incapacidade, sofrimento, perda da autoestima, isolamento social, gastos financeiros, afastamento do trabalho, e alterações psicossociais (DANTAS, 2012).

Morais (2008) relata que a avaliação da ferida é de fundamental importância para um bom tratamento, pois uma avaliação equivocada pode ocasionar dor, aumentar a lesão, e elevar o custo e o tempo de tratamento. Cunha (2006) ressalta ainda que avaliação de feridas possui deferentes etapas, dentre elas relacionada a sua localização, extensão (comprimento e largura, profundidade ou túnel), exsudato (quantidade, aspecto e odor), leito (tipo de tecido exposto, classificação quando aplicável), margem (regular ou não, macerada, hiperqueratose, epitelização), pele perilesional (integra, lesionada, ressecada, hiperpgmentada, hiperemia e flictemias) e quanto a dor.

O processo de cicatrização tem por finalidade a cura das feridas, com isso vários protocolos são disponibilizados para processo final, a fitoterapia é um dos protocolos utilizados para cicatrização de feridas dentre eles a utilização da própolis que é um produto natural advindo de abelhas produzidos por resinas. A própolis segundo Sahinler (2005) é um produto adquirido através de um material resinoso advindos de abelhas Apis mellífera $L$. é um produto natural que possui propriedades antioxidante, atuando na defesa do organismo contra os radicais livres encontrados em todos os organismos. Na composição são encontrados constituintes químicos que atuam na proteção de doenças crônicas ocasionadas pelo estresse oxidativo como o câncer e doenças metabólicas (CALEGARI, 2017). A própolis verde de Baccharis dracunculifolia DC, mas conhecida como alecrim-do-campo e contém 3,1 a $3,3 \%$ de minerais, 9,8 a 10,6\% de proteína bruta (CP), 45,7 a 48,7\% de lipídeos e 15,9 a 20,9\% de fibra (MACHADO et al, 2016). Sua composição é principalmente de ácido 3,5diprenil-4-hidroxicinâmico (GUIMARÃES et al, 2012), possuindo antioxidante (WO'ZNIAK et al, 2019), antibacteriano (PEREIRA et al, 2019), antifúngica, antiviral, (BABINSKA et al, 2012), anti-inflamatório (KHORASGANI et al, 2010), atividades antigenotóxicas e antimutagênicas (ROBERTO et al, 2016). Este artigo tem como objetivo relatar o efeito cicatrizante da própolis verde em lesão cutânea.

\section{RELATO DE CASO}

Paciente do sexo feminino, 52 anos, fez-se a procura de uma assistência médica para uma avaliação no Membro Inferior Esquerdo (MMII), de uma lesão cutânea, sofrida após duas semanas do ocorrido.

Ao exame físico no momento de inspeção, foi observado que a paciente ao deambular, claudicava devido a mialgia acometida no membro, edema devido ao processo inflamatório e com a pele de cor escura ao redor da ferida. Segundo o examinador a lesão era tida como micose, para melhores informações, foi realizado exame complementar, um hemograma, na qual a paciente encontra-se em seu quadro clínico em perfeitas condições, exceto colesterol total com $169,00 \mathrm{mg} / \mathrm{dl}$.

Ao ser avaliada o examinador orientou medicamentos para o processo de reparação da ferida como, um antibiótico Levofloxacino de 500mg com posologia de 12/12 e um analgésico Dievari de 900mg $+100 \mathrm{mg}$ na qual sua posologia era uma vez por dia.

A após uma segunda avaliação externa foi observado que as feridas tinham o formato assimétrico, profundas, edemaciado, com um formato numular, apresentando mialgia no membro ao deambular e ao deitarse. A dor referida pela paciente antes de iniciar o tratamento de 0 a 10 de acordo com a Escala Visual Analógica - EVA, foi de 9, significando dor intensa, dor a qual dificultava na vida diária assim como a dificuldade para dormir, pois segundo relato passava noites acordada por falta de posições ao manter o membro em posição de 
conforto. Porem devido a inúmeros sinais e sintomas observados, as feridas não apresentavam odores.

A própolis foi utilizada na lesão, porém antes de ser utilizada foi realizada assepsia no local como meio de higienização. Na assepsia foram utilizados luvas, gazes, soro fisiológico, sabonete antisséptico Riohex de $2 \%$ de Digliconato de Clorexidina, água oxigenada de 10 volumes de $100 \mathrm{ml}$ e o extrato de própolis verde de $30 \mathrm{ml}$. O procedimento foi realizado durante oito dias, ate obter o resultado de reparação da lesão.

Figura 1 - Evolução das fases de cicatrização do ferimento tratado com extrato de própolis verde.
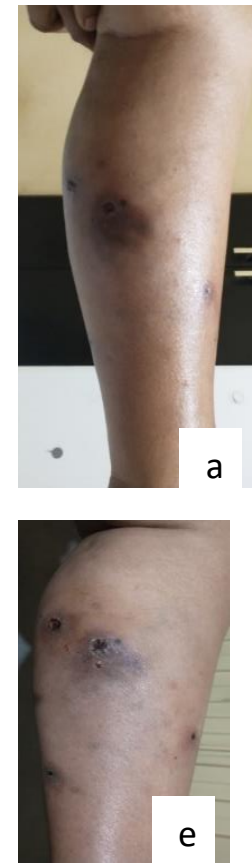
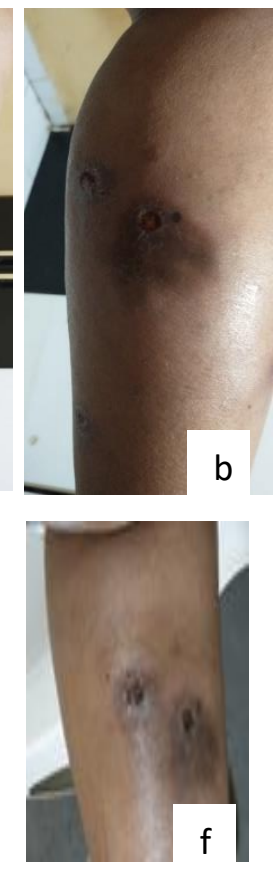
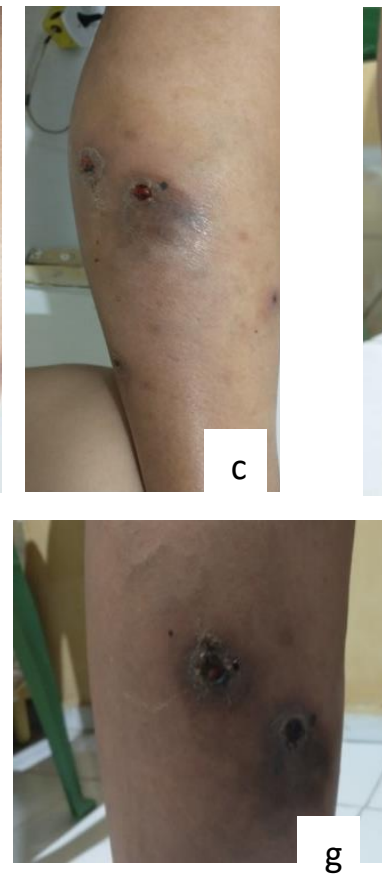

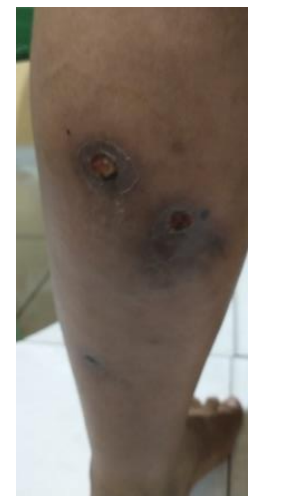

d

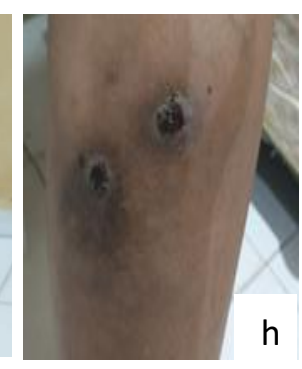

Fonte: autores (2020).

\section{DISCUSSÃO}

As feridas abertas são classificadas de acordo com sua profundidade como observado na (figura 1), na qual são observadas seu grau de complexidade, contaminação e natureza do agente que a ocasionou. No caso da contaminação a classificação tem sua importância na prática do tratamento. $\mathrm{Na}$ figura 1 , o ferimento apresenta estágio I, pois ocorreu somente o comprometimento da epiderme, acompanhado de eritema em pele integra e sem ocorrência na perda de tecido. A figura 1, à ferida está exposta sem procedimento de protocolo e não apresenta nenhum dos fatores para o processo de reparação.

A partir do primeiro dia de atendimento, foi realizada assepsia no local da lesão como forma de higienização, na prevenção da entrada de agentes patogênicos, após o procedimento antisséptico, introduziuse o extrato da própolis verde. Com isso durante os dias de aplicação foram observadas as mudanças da morfologia da ferida, iniciando o processo de reparação. "Procedimento antisséptico funciona como forma de eliminar ou minimizar o desenvolvimento de vírus, fungos e bactérias quando utilizados sobre a pele e mucosa" (REIS, 2011 p. 871). Mariano e Hori (2018) ressaltam que a própolis apresentam uma grande eficácia em diferentes modelos antimicrobianos. E sua atividade antibacteriana atua principalmente em bactérias gram-positivas, e uma eficácia contra Escherichia coli. Sua atividade como antiinflamatório está relacionada a grande capacidade de aumentar a atividade bactericida dos macrófagos, diminuindo citocinas pró-inflamatórias e aumentando citocinas anti-inflamatórias.

As mudanças morfológicas são dívidas em três processos para chegar ao estado de cicatrização, temos a etapa inflamatória, a etapa proliferativa e a etapa de maturação.

A figura 1 demonstra a ferida sem aplicação do protocolo, onde se observa a fase inicial da lesão, a fase inflamatória que tem como duração 48 a 72 horas, esse processo é caracterizado por: dor, calor, edema e rubor. Após a aplicação a ferida ainda demonstrava um processo inflamatório ainda característico isso ilustrado nas figuras 2 a 4, entre o primeiro ao terceiro dia. Essa etapa se da no momento que inicia a lesão. Que segundo Broughton (2007) é quando os macrófagos migram para ferida, e são consideradas as principais células antes dos fibroblastos migrarem e dar início a replicação.

A partir do quarto dia entre as ilustrações 5 a 7 a lesão começa a seguir para segunda etapa, denominada etapa proliferativa que se estende por 12 e 14 dias é caracterizada pela reconstituição de vasos sanguíneos e linfáticos devido a produção de colágeno, a cicatriz começa a ter um aspecto avermelhado. Lawrence (1994) ressalta que é uma fase constituída por quatro etapas: epitelização, angiogênese, formação de tecido de granulação e deposição de colágeno. Essa fase se inicia no $4^{\circ}$ dia depois da lesão se estendendo aproximadamente ao término da segunda semana. 
E por fim seguindo com os procedimentos deu-se início ao terceiro processo denominado fase de maturação ou remodelamento, observado nas figuras 8 a 9 entre o sétimo ao oitavo dia de tratamento, sua duração é por tempo indeterminado, tem por característica principal a reorganização do colágeno. A cicatrização se apresenta a uma coloração semelhante à pele adjacente. Segundo Broughton (2006) diz que nessa fase a principal característica é a deposição de colágeno de uma maneira organizada, ressalta ainda que a cicatrização tem sucesso quando ocorre um equilíbrio entre a síntese da matriz nova e a lise da matriz antiga, demonstrando sucesso quando a deposição é maior. O autor comenta que mesmo depois de um ano a ferida pode apresentar um colágeno menos organizado do que a pele sã, e a força tênsil jamais voltará a ser $100 \%$, podendo em três meses atingir $80 \%$ apensas.

\section{CONCLUSÃO}

Considerando as informações apresentadas, percebeu-se a ação da própolis verde para o processo de reparação de uma lesão cutânea. No relato de caso, a própolis verde, durante a aplicação do protocolo, contribuiu para o processo de reparação do tecido, ocasionando a diminuição do processo inflamatório, ocasionando analgesia local, pois de acordo com a Escala Visual Analógica - EVA, relatada pela paciente com grau 9, dor intensa no local, após a aplicação foi relatado a redução para 0 de dor, favorecendo redução do edema, deambulação satisfatória.

\section{RECOMENDAÇÕES}

Por se tratar de um relato de caso, é importante um estudo com grupo controle e demais variáveis que possibilitem obter resultados precisos e significativos sobre a ação do extrato em estudo e sua aplicação para tratamento de feridas.

\section{REFERÊNCIAS}

BLANES L. Tratamento de feridas: Cirurgia vascular, guia ilustrado. São Paulo: 2004.

BRASIL. Manual de condutas para tratamento de úlceras em hanseníase e diabetes. Ministério da Saúde, Secretaria de Vigilância emSaúde, Departamento de Vigilância Epidemiológica. - 2. ed. rev. e ampl. Brasília: Ministério da Saúde [Internet]. 2008[cited 2020 nov. 12]. Available from:

http://bvsms.saude.gov.br/bvs/publicacoes/manual_condu tas_ulcera_hanseniase.pdf.

BROUGHTON G., 2nd, JANIS J.E, ATTINGER C.E. The basic science of wound healing. Plast Reconstr Surg 2006; 117(7 Suppl):12S-34S. disponível em: https://www.scielo.br/scielo.php?script=sci_arttext\&pid= S0102-67202007000100010. Acessado no dia 13 de nov.2020.

BROUGHTON G., 2nd, JANIS J.E; ATTINGER C.E, Wound healing: an overview. Plast Reconstr Surg 2006; 117(7 Suppl):1e-S-32e-S. disponível em: https://www.scielo.br/scielo.php?script=sci_arttext\&pid=
S0102-67202007000100010. Acessado no dia 13 de nov. 2020 .

CALEGARI, M.A.; PRASNIEWSKI, A.C.; SILVA, C.; SADO, R.Y.; MAIA, F.M.C.; TONIAL, L.M.S.; OLDONI, T.L.C, Propolis from Southwest of Parana produced by selected bees: influence of seasonality and food supplementation on antioxidante activity and phenolic profile. An. Acad. Bras. Ciênc. 2017 Feb;89(1):45-55. Disponivel em: https://www.scielo.br/pdf/babt/v63/1516-8913-babt-63e20190408.pdf. Acessado no dia 12 de nov. 2020.

CUNHA N.A. Sistematização da assistência de enfermagem no tratamento de feridas crônicas. 2006

DANTAS, D.V.; TORRES, G.V.; DANTAS, R.A.N, Assistência aos portadores de feridas: caracterização dos protocolos existentes no Brasil. Ciência, cuidado e saúde. 2012;10(2):366-372.

GUimaRÃES, N. S. S.; MELlO, J. C.; PAIVA, J. S.; BUENO, P. C. P.; BERRETTA, A. A.; TORQUATO, R. J.; NATES, I. L. and RODRIGUES, T. 2012. Baccharis dracunculifolia, the main source of green propolis, exhibits potent antioxidant activity and prevents oxidative mitochondrial damage. Food and Chemical Toxicology 50:1091-1097. https://doi.org/10.1016/j.fct.2011.11.014. Disponivel em: https://www.scielo.br/pdf/rbz/v49/1806-9290-rbz-49e20190198.pdf. Acessado no dia 12 de nov. de 2020.

KHORASGANI, E. M.; KARIMI, A. H. and NAZEM, M. R. 2010. A comparison of healing effects of propolis and silver sulfadiazine on full thickness skin wounds in rats. Pakistan Veterinary Journal 30:72-74. Disponivel em: https://www.scielo.br/pdf/rbz/v49/1806-9290-rbz-49e20190198.pdf. Acessado no dia 12 de nov. de 2020.

LAWRENCE, W.T.; DIEGELMANN, R.F, Growth factors in wound healing. Clin Dermatol 1994; 12(1):157-69. disponível em: https://www.scielo.br/scielo.php?script=sci_arttext\&pid= S0102-67202007000100010. Acessado no dia 13 de nov. 2020 .

MACHADO, B. A. S.; SILVA, R. P. D.; BARRETO, G. A.; COSTA, S. S.; SILVA, D. F.; BRANDÃO, H. N.; ROCHA, J. L. C.; DELLAGOSTIN, A. O.; HENRIQUES, J. A. P.; UMSZA-GUEZ, M. A. and PADILHA, F. F. 2016. Chemical composition and biological activity of extracts obtained by supercritical extraction an ethanolic extraction of brown, green and red propolis derived from different geographic regions in Brazil. PLoS ONE 11:e0145954. https://doi.org/10.1371/journal.pone.0145954 Disponivel em: https://www.scielo.br/pdf/rbz/v49/1806-9290-rbz-49e20190198.pdf. Acessado no dia 12 de nov. de 2020.

MARIANO, M. d. M.; HORIA, J. I. O potencial terapêutico da própolis verde Brasileira. E-Revista. 2018 . 
MORAIS G.F.D.C.; OLIVEIRA, S.H.D.S.; SOARES, M.J.G.O, Avaliação de feridas pelos enfermeiros de instituições hospitalares da rede pública. Texto \& contexto enferm. 2008; 98-105.

PINHEIRO, A. R. M.; ALEXANDRE, S. G.; MEDEIROS, A. B. F.; SILVA, F. M.; LIMA, M. C. G. A.; TEIXEIRA, A. K. S, Protocolo: prevenção de pele, 2014.

PEREIRA, C. A.; COSTA, A. C. B. P.; LIPORONI, P. C. S.; REGO, M. A. and JORGE, A. O. C. 2016. Antibacterial activity of Baccharis dracunculifolia in planktonic cultures and biofilms of Streptococcus mutans. Journal of Infection and Public Health 9:324-330. https://doi.org/10.1016/j.jiph.2015.10.012 Disponivel em: https://www.scielo.br/pdf/rbz/v49/1806-9290-rbz-49e20190198.pdf. Acessado no dia 12 de nov. de 2020.

REIS, Carmelia. Apostilha de lesões elementares, 2011.

REIS, L. M. dos et al. Avaliação da atividade antimicrobiana de antissépticos e desinfetantes utilizados em um serviço público de saúde. Rev. bras. enferm., Brasília, v. 64, n. 5, Out. 2011.

REIS, D.B.; PERES, G.A.; ZUFFI, F.B.; FERREIRA, L.A.; POGGETTO, M.T.D, Care for people with venous ulcers: the perception of nurses in the family health strategy. Rev Min Enferm [Internet]. 2013[cited 2020 nov. 12];17(1):101-6. Available from: http://www.reme.org.br/content/ imagebank/pdf/v17n1a09.pdf.

ROBERTO, M. M.; MATSUMOTO, S. T.; JAMAL, C. M.; MALASPINA, O. and Marin-Morales, M. A. 2016. Evaluation of the genotoxicity/ mutagenicity and antigenotoxicity/antimutagenicity induced by propolis and Baccharis dracunculifolia, by in vitro study with HTC cells. Toxicology in Vitro 33:9-15. https://doi.org/10.1016/j.tiv.2016.02.005 Disponivel em: https://www.scielo.br/pdf/rbz/v49/1806-9290-rbz-49e20190198.pdf. Acessado no dia 12 de nov. de 2020.

SAHINLER N, Kaftanoglu O. Natural product propolis: chemical composition. Nat. Prod. Res. 2005; 19(2): $183-$ $188 . \quad$ Disponivel em: https://www.scielo.br/pdf/babt/v63/1516-8913-babt-63e20190408.pdf. Acessado no dia 12 de nov. 2020.

WOŹNIAK, M.; MRÓWCZYŃSKA, L.; WAŚKIEWICZ, A.; ROGOZIŃSKI, T. and RATAJCZAK, I. 2019. The role of seasonality on the chemical composition, antioxidant activity and cytotoxicity of Polish propolis in human erythrocytes. Revista Brasileira de Farmacognosia 29:301-308. https://doi.org/10.1016/j.bjp.2019.02.002 Disponivel em: https://www.scielo.br/pdf/rbz/v49/1806-9290-rbz-49e20190198.pdf. Acessado no dia 12 de nov. de 2020. 